\title{
UN MAGISTERIO EN LA DISTANCIA: LA RELACIÓN EPISTOLAR ENTRE LOS ENTOMÓLOGOS JOSÉ MARÍA DUSMET Y MODESTO QUILIS
}

\author{
Jesús I. Catalá-Gorgues \\ Universidad Cardenal Herrera-CEU, CEU Universities. Valencia. \\ jicatala@uchceu.es \\ ORCID iD: https://orcid.org/0000-0001-5713-725X
}

Recibido: 23 septiembre 2016; Aceptado: 14 febrero 2017.

Cómo citar este artículo/Citation: Catalá-Gorgues, Jesús I. (2018), “Un magisterio en la distancia: la relación epistolar entre los entomólogos José María Dusmet y Modesto Quilis", Asclepio, 70 (1): p214. https://doi.org/10.3989/asclepio.2018.07

RESUMEN: José María Dusmet (1869-1960) fue un reconocido entomólogo español, especialista en macrohimenópteros, que desarrolló su labor vinculado al Museo Nacional de Ciencias Naturales aun sin ocupar oficialmente puesto alguno. En 1925 un joven universitario de Valencia, Modesto Quilis (1904-1938), contactó con él para solicitarle consejo para progresar en su afición por los insectos. A partir de ese momento, y durante más de diez años, Dusmet fue iniciando a Quilis en la práctica entomológica profesional. Así, le asesoraba en la adquisición de ejemplares y bibliografía, al tiempo que le facilitaba contactos entre especialistas nacionales y extranjeros y le resolvía dudas de nomenclatura y taxonomía. Además, le inició en un cierto ethos caballeresco de la práctica naturalista. Con el tiempo, Quilis logró una inserción profesional como entomólogo especialista en microhimenópteros y control biológico de las plagas del campo, iniciando una prometedora carrera que frustró su temprana muerte. Las cartas que ambos intercambiaron, conservadas en el Museo Nacional de Ciencias Naturales, ponen de relieve los detalles de un magisterio en la distancia intensamente cargado de admiración mutua y cultivo de la amistad.

PALABRAS CLAVE: Historia natural; entomología; correspondencia científica; sentimientos en la ciencia; España.

\section{A TEACHING IN THE DISTANCE: THE CORRESPONDENCE BETWEEN JOSÉ MARÍA DUSMET AND MODESTO QUILIS, AND THE ENTOMOLOGICAL PRACTICE IN SPAIN BEFORE CIVIL WAR}

ABSTRACT: José María Dusmet (1869-1960) was a renowned Spanish entomologist. He specialized in big Hymenoptera, developing his tasks at the National Museum of Natural Sciences in Madrid, despite the fact he never occupied an official position. In 1925, Modesto Quilis (1904-1938), a student from Valencia, wrote Dusmet in order to obtain advice on how to make progress in entomological studies. From that moment and for more than a decade, Dusmet gave Quilis guidance to the practice of professional entomology in a diversity of aspects, e.g., acquisition of specimens and bibliography, contacts with other colleagues in Spain and other countries, or questions on taxonomy and nomenclature. He also introduced his young disciple in a certain kind of scientific ethos, based on a chivalric sense of the relationship between natural history practitioners. Some years went by and Quilis obtained an official job as entomologist specialized in microhymenoptera and pest control. His promising career was cut short by his premature death. Exchange letters between both naturalists have been consulted at the Archive of the National Museum of Natural History. This correspondence highlights the details of a sort of teaching-in-distance, pervaded by friendship and mutual admiration.

KEY WORDS: Natural history; entomology; scientific letters; feelings in science; Spain.

Copyright: @ 2018 CSIC. Este es un artículo de acceso abierto distribuido bajo los términos de la licencia de uso y distribución Creative Commons Reconocimiento 4.0 Internacional (CC BY 4.0). 


\section{INTRODUCCIÓN}

A comienzos del siglo XX la entomología ocupaba un lugar muy destacado en el conjunto de la ciencia española (Compte, 1988). La presencia de una figura de relieve internacional como es Ignacio Bolívar (1850-1944), catedrático de Zoología de Articulados en la Universidad de Madrid desde 1877 y especialista en ortópteros, pero sobre todo dinamizador de los estudios naturalistas desde su puesto de director del Museo Nacional de Ciencias Naturales (MNCN) y por su vínculo con la Junta para la Ampliación de Estudios (JAE), que llegó a presidir en 1934, es sin duda un factor clave en el desarrollo que la ciencia de los artrópodos alcanzó por aquella época. Su empeño modernizador le llevó a implicar a un número considerable de naturalistas, muchos de ellos miembros de la Real Sociedad Española de Historia Natural (RSEHN), en la mejora de la precaria situación en que se encontraban las colecciones de ejemplares y las bibliotecas especializadas, lastre para la equiparación de la práctica naturalista española a la de otros países (Casado, 2006a; Puig-Samper, 2016; Sanz, 1992). En todo caso, la entomología patria, como otras especialidades, no estaba en modo alguno reducida a los ámbitos institucionales madrileños donde Bolívar y sus colaboradores directos actuaban, de modo que otros grupos y redes se conformaron en Cataluña, fundamentalmente en torno al Museu de Ciències Naturals de Barcelona (MCNB) y la Institució Catalana d'Història Natural (ICHN); Aragón, con las diversas iniciativas encabezadas por el jesuita Longinos Navás (1858-1938); y por supuesto, con la acción de un número no despreciable de naturalistas radicados en otras regiones, muchos de ellos aficionados que encontraron mejores posibilidades de divulgar sus estudios gracias a la creciente oferta de asociacionismo naturalista y de revistas vinculadas al mismo (Bach, Compte, 1997). El primer tercio del siglo XX también conoce el establecimiento de las estaciones de fitopatología, con una vertiente entomológica aplicada muy conspicua (Catalá, Guillem, 2006). La situación española, por otro lado, a pesar de retrasos e inercias, refleja la de la comunidad internacional. El inicio de los Congresos Internacionales (el primero en Bruselas, en 1910), la aparición de revistas especializadas o la generalización de los servicios de entomología agrícola y control de plagas caracterizan el inicio del siglo como un período de notable proyección para la disciplina (Aguilar, 2006; Chapman, 2000; Hagen, Franz, 1973; Jones, 1973). Y en cuanto ciencia recolectora, la entomología ya estaba, en España y en el mundo, en esa «age of survey» (Kohler, 2006) que superaba la exploración extensiva a la búsqueda de novedades en lugares remotos, para centrarse en ámbitos geográficos próximos y conocidos, en los cuales se coleccionaba metódicamente para asentar el conocimiento de la biodiversidad local.

El relativo florecimiento de la entomología española (y de la historia natural en general) fue acompañado de tensiones y enfrentamientos, que derivaban tanto de querellas personales como de luchas por el control institucional, reflejo de la intensa polarización ideológica que se había construido en España en torno a la ciencia (Sala, 1982; Catalá 2003b). Es en este ambiente, simultáneamente esperanzador, tenso y precario, donde desarrolló su tarea José María Dusmet y Alonso (1869-1960) (figura 1).

Figura 1. Retrato de madurez de José María Dusmet

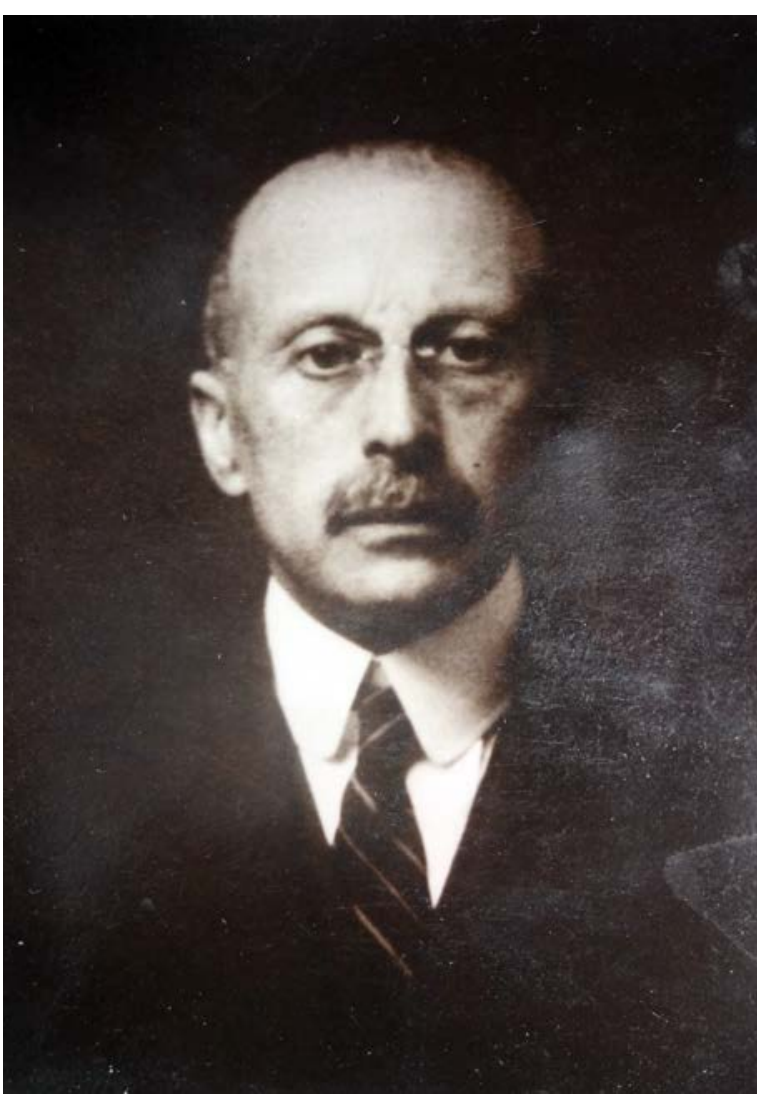

Fuente: Archivo personal de Teo Alonso-Pesquera.

Especialista en himenópteros, con una serie de trabajos muy relevantes centrados en la taxonomía y diversidad de los ápidos y de diferentes grupos de avispas de la fauna española, fue, en cierto modo, una figura de consenso en las difíciles relaciones entre grupos de diversas lealtades. Dusmet, que estudió 
la carrera de ciencias naturales, habiendo obtenido el doctorado en 1894, desarrolló su labor científica en el $\mathrm{MNCN}$, aunque con un vínculo bastante informal, como naturalista agregado. ${ }^{1}$ El notable patrimonio de que gozaba su familia le permitió desarrollar esa labor, con dedicación casi diaria, sin la necesidad de una prestación remunerada, lo que hace a Dusmet inclasificable en la típica dicotomía profesional-aficionado. Su trabajo en el MNCN le situaba en la órbita de los colaboradores de Bolívar (Bach, Compte, 1997); sin embargo, conservador como era en lo ideológico, y alejado en ese aspecto del director del centro, prestó apoyo a las iniciativas impulsadas por Navás, especialmente en la fundación de la Sociedad Aragonesa de Ciencias Naturales (SACN) (1902) -aunque nacido en Chinchón y residente en Madrid, Dusmet se sentía muy vinculado al municipio zaragozano de Ambel, donde mantenía posesiones que visitaba anualmente- y de la Sociedad Entomológica de España (SEE) (1918) (Catalá, 2003a).

En el presente trabajo vamos a explorar un aspecto diferente de la actividad de Dusmet: su faceta de maestro de otros entomólogos. ${ }^{2}$ Para ello, estudiamos su relación con el valenciano Modesto Quilis Pérez (1904-1938) (figura 2).

Según refería este último (Quilis, 1927), fue iniciado en el estudio de los insectos por Emilio Moróder (1882-1939), conservador del museo de historia natural de la Universidad de Valencia y especialista en coleópteros. El joven, sin embargo, acabó optando por los himenópteros, lo que le llevó a entrar en contacto con Dusmet. Desde 1925, este guió los pasos del principiante, todavía estudiante de farmacia, ejerciendo un magisterio en la distancia a través de una asidua correspondencia epistolar salpicada por encuentros personales esporádicos en las raras ocasiones en que Quilis podía desplazarse a Madrid. En el Archivo del Museo Nacional de Ciencias Naturales (ACN) se conservan muchas de las cartas cruzadas entre ambos. Además de las originales de Quilis, guardadas por Dusmet con el resto de su correspondencia científica, hay copias de las escritas por Dusmet. Al poco de establecer relación, este ya mecanografiaba sus cartas y sacaba calco de las mismas. En total, son 101 las cartas conservadas que intercambiaron, 60 escritas por Quilis y 41 por Dusmet, en el período en que mantuvieron correspondencia, 1925-1936, mayoritariamente concentradas en la primera mitad del mismo. ${ }^{3}$

El ejercicio magisterial a través de la correspondencia ha sido objeto de diversos estudios en la historia de la historia natural. Así, Schwartz $(1995,2010)$ ha
Figura 2. Retrato de Modesto Quilis

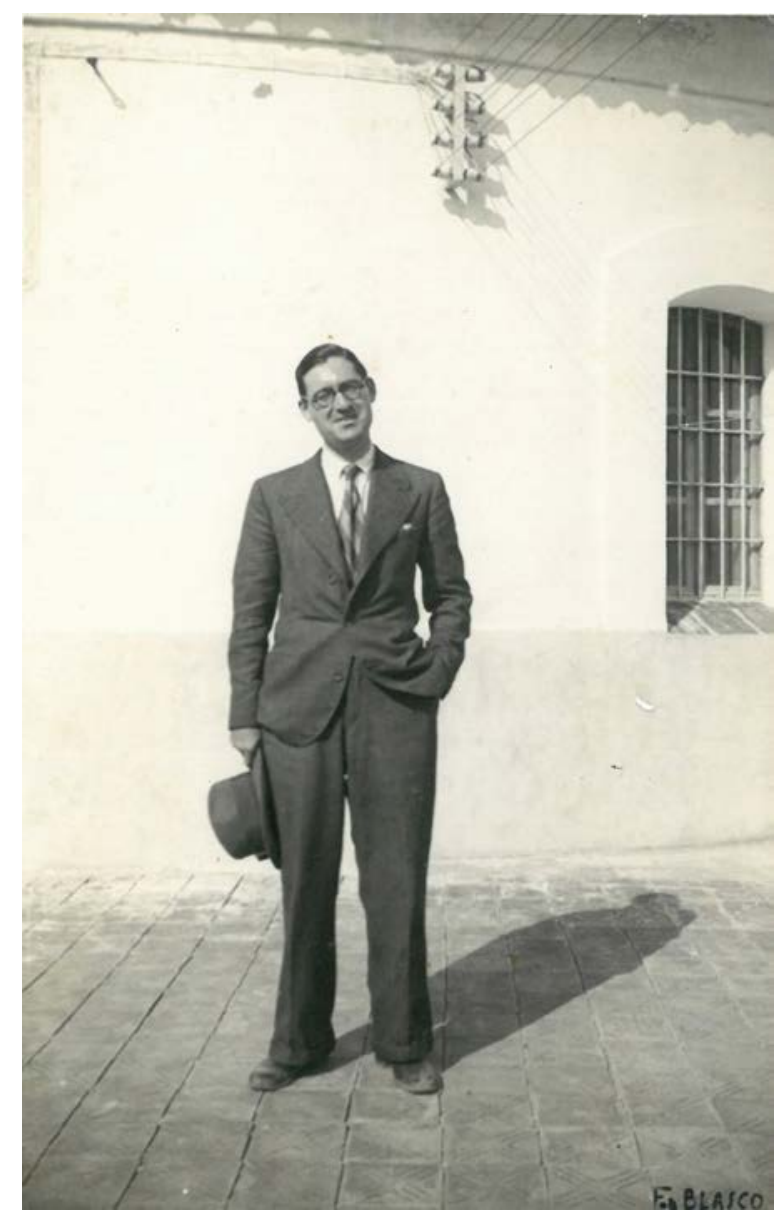

Fuente: Archivo de la familia Quilis Llopis.

abordado la relación entre Charles Darwin y George Romanes básicamente a través de las cartas. Una relación establecida, como en el caso que nos ocupa, in absentia, aunque allí fue el maestro quien contactó con el discípulo en 1873, tras leer una carta de Romanes en Nature donde defendía una interpretación darwinista de los patrones de coloración en peces. Para la historia natural española, algunos estudios contenidos en un monográfico de Afers (Camarasa, Vidal, 2006) muestran diferentes aspectos de las relaciones maestro-discípulo a través de la correspondencia. Así, Casado (2006b) explora el control distante del Laboratorio de Hidrobiología Española de Valencia que ejerció Celso Arévalo desde Madrid a través de su discípulo Luis Pardo; un caso muy distinto al de Dusmet y Quilis, en el sentido de que aquí fueron las cartas las que permitieron mantener un magisterio iniciado en las aulas del Instituto General y Técnico de Valencia. Las estrategias legitimadoras de la pro- 
pia labor científica que transmiten los epistolarios están también presentes en el estudio sobre la relación entre Linneo y un Pehr Löfling desplazado a España que, imbuido de la lealtad por el maestro, maniobra para difundir las doctrinas de este (Pelayo, 2006). Y en el orden de la economía material de la ciencia, el estudio de Vidal (2006) pone de relieve cómo Federico Trémols, hombre de la academia, instruía a Juan Joaquín Rodríguez Femenias, aficionado riguroso, en las técnicas botánicas y la selección del material para los herbarios. El «diálogo por ausencia» que generan las cartas, y más en la época contemporánea, cuando el sentido de privacidad de la correspondencia ha dejado de lado el uso de la carta como documento de difusión pública de ideas (Salavert, 2006), permite también acceder al ámbito de los sentimientos y de la «economía emocional de la ciencia» (cf. White, 2009). A fin de cuentas, la historia natural ha sido frecuentemente justificada desde la apelación a las experiencias que engendra en lo emotivo (Jardine, Spary, 1996). En lo que sigue, vamos a tratar de abordar estos planos en la relación entre Dusmet y Quilis, en un intento no solamente de reconstruir un magisterio en la distancia, sino también de dar luz sobre la práctica entomológica en la España de la Dictadura de Primo de Rivera y la II República.

\section{LOS PRIMEROS PASOS DE UN ENTOMÓLOGO}

Principiaba el año 1925, cuando el joven Quilis decidió escribir a Dusmet la carta que abriría su intensa relación científica. En dicha misiva exponía su afición por los himenópteros, «que en esta región están muy poco explorados», y se encomendaba a Dusmet por ser "uno de los mejores especialistas en este grupo». También le sondeaba sobre la posibilidad de que le clasificara sus capturas y le pedía consejo en la adquisición de libros sobre dicho orden de insectos. ${ }^{4}$

Aunque la respuesta no ha podido ser hallada, no hay duda de que Dusmet se dio prisa en atender a su nuevo corresponsal, pues este le volvió a escribir apenas ocho días después. Le agradecía las separatas que le enviaba y unas cajas de himenópteros llegadas con antelación por conducto de Antimo Boscá (18741950), catedrático de historia natural del Instituto de Segunda Enseñanza de Valencia y autor de trabajos zoológicos, arqueológicos y paleontológicos (Camarasa, Catalá, 2007). Dusmet había atendido al ruego de Quilis relativo a la determinación de sus ejemplares; teniendo en cuenta la rapidez del despacho, es posible que Boscá hiciera de mediador entre ambos, llevando personalmente las cajas a Madrid y devolviéndolas a Valencia. Quilis comentaba también que estaba siguiendo la obra de Jules de Gaulle (1850-1922) sobre los himenópteros de Francia para su trabajo de determinación y clasificación y le pedía opinión sobre la misma. ${ }^{5}$ Expresaba también sus dificultades a la hora de reconocer determinados caracteres morfológicos, algo esperable en alguien que apenas se estaba iniciando seriamente en la labor de determinación precisa de especies entomológicas. ${ }^{6}$

Hacia finales de año, Quilis se había convertido en suministrador de Dusmet -su «Maestro en Himenopterología» como le llamaba- de ejemplares de géneros en los cuales este estaba trabajando, mientras que el neófito ya iba decantando sus preferencias a favor de géneros como Bombus, con el que debutaría como autor (Quilis, 1927). ${ }^{7}$

Al año siguiente Quilis reconocía que sin el apoyo de Dusmet nunca hubiera pensado en publicar nada y que «tal vez se hubiese muerto en mí la afición, la enorme afición que hoy tengo a los Himenópteros». ${ }^{8}$ Un sentido de la imitación al maestro aparece de forma explícita en estos inicios de la relación. Así se pone en evidencia cuando Quilis valora una nueva publicación de Dusmet, con un énfasis muy marcado en cuán difícil le será igualar a su maestro:

"[Leí] su trabajo sobre los géneros Eucera y Macrocera. [L]e felicito efusivamente por él pues ahora veo lo que publicar un trabajo de esta índole representa. Es un trabajo ímprobo». ${ }^{9}$

Y en otra carta:

«Ahora comprendo yo, lo que le habrán costado de hacer los numerosos y bien escritos trabajos que $\mathrm{Vd}$. ha publicado y que sigo como modelo de los míos». ${ }^{10}$

La imitación se acompañaba de la fidelidad. Quilis concebirá sus investigaciones sobre ápidos como la continuación del trabajo emprendido por Dusmet, hasta el punto que titulará sus primeras publicaciones de modo semejante a como procedía este último: bajo el epígrafe general de "Los Ápidos de España", un subtítulo con el género al que se consagraba el estudio. De hecho, antes de haberse decantado por Bombus, planteó un estudio sobre el género Osmia en los términos que siguen:

«[E]n cuanto a la forma del trabajo, será excelente el imitar a los suyos, para que haya uniformidad en la publicación de los Ápidos y el día de mañana puedan recopilarse todas estas monografías en una sola obra». ${ }^{11}$

El compromiso voluntario de Quilis respecto a Dusmet fue más allá, pues, de la mera iniciación en la 
práctica científica para adquirir un carácter misional: la continuidad de la obra del maestro. ${ }^{12}$

La elección de Osmia, un género «al que me he aficionado un tanto pues me gusta mucho» -tanto, de hecho, como para fantasear con una obra sobre la especies valencianas de Osmia con láminas en color-, ${ }^{13}$ fue por propia iniciativa de Quilis. Hecha la elección a las puertas del verano, pudo reportar al final del mismo una exitosa temporada de capturas. ${ }^{14}$ Para Dusmet, el género Osmia era «interesante, numeroso y no estudiado aún en España». La aprobación que conllevaban estas palabras se acompañó de referencias a bibliografía básicamente alemana y del ofrecimiento de contactos con los especialistas Otto Schmiedeknecht (1847-1936), de Bad Blankenburg (Turingia, Alemania), y Raymond Benoist (1881-1970), del Museo de París. Además, ponía a disposición de Quilis sus ejemplares de Osmia, que estimaba en más de 1.600, aunque solamente «cuando ya haya V. ido clasificando las suyas", para no abrumarlo. Y terminaba reiterando que «para todo lo que le pueda ayudar estoy a su disposición [...]. Como siga así, llegará V. a cosechar triunfos científicos». ${ }^{15}$

Este plan de trabajo se modificó sustancialmente a finales de 1926, al llegarle a Quilis una propuesta de Luis Pardo (1897-1958), por entonces profesor ayudante en el Instituto de Valencia y encargado del Laboratorio de Hidrobiología. El Instituto, desde 1916 y coincidiendo con los primeros años de funcionamiento del Laboratorio, mantenía una revista, los Anales del Instituto Nacional de 2. a Enseñanza de Valencia, donde publicaban sus estudios profesores del propio centro junto a investigadores foráneos, con especial protagonismo para aquellos vinculados al Laboratorio y a la sección de Valencia de la RSEHN (Catalá, Azkárraga, 2015). Diez años después, sin embargo, el Laboratorio atravesaba una difícil situación institucional, pues el MNCN, del cual teóricamente dependía, no lo dotaba adecuadamente, por lo que mantenerlo abierto suponía una importante carga para el Instituto; a ello había que sumar la no menos precaria situación laboral de Pardo (Casado, 1997), y de ahí que reivindicar la continuidad implicara, entre otras cosas, mantener viva la revista.

Quilis le expuso la propuesta a Dusmet. Puesto que Pardo quería que el artículo saliera en el siguiente volumen, pero el trabajo que generaba Osmia impedía cumplir con ese plazo, se planteó cambiar de objetivo y centrarse en Bombus, un género con pocas especies españolas y para el cual contaba con bastantes ejemplares. ${ }^{16}$ Dusmet consideró acertada la decisión. Como era un género que "no pensaba estudiarlo», puso a disposición de Quilis 350 ejemplares, tanto cazados por él como determinados por colegas extranjeros. ${ }^{17}$ Quilis se preocupó de entrar en contacto con especialistas en Bombus. Recién comenzado 1927, pedía a Dusmet la dirección de Oskar Vogt (1870-1959), ${ }^{18}$ eminente neurobiólogo y uno de los mayores expertos en el género (Boer, 2004). Dusmet se la facilitó y se apresuró a escribir al alemán con el objeto de reclamarle la devolución de los ejemplares de Bombus que le había prestado para sus estudios sobre variabilidad, pues quería cedérselos a Quilis. ${ }^{19}$ Vogt accedió a colaborar con los españoles a través del neurofisiólogo Rafael Lorente de Nó (1902-1990), ${ }^{20}$ que por aquel tiempo se encontraba investigando en Berlín con una pensión de la JAE (Baratas, 2010).

Encauzada ya la vocación de Quilis, Dusmet le planteó la necesidad de estudiar las colecciones del MNCN y del MCNB, pues solamente de ese modo alcanzaría su trabajo «la necesaria amplitud y conozca todo (puede decirse) lo de España». ${ }^{21}$ Quilis negoció con Ascensi Codina (1877-1932), del MCNB, el envío de ejemplares allí depositados. ${ }^{22}$ Le llegaron más de 250 de los géneros Bombus y del género afín (hoy considerado subgénero) Psithyrus. ${ }^{23}$ En cuanto al MNCN, había pensado visitarlo en junio, pero la perentoriedad de presentar el trabajo a los Anales le impidió hacer efectivo el plan. Por ello, escribió a Dusmet:

“Me veo obligado a molestarle con una petición delicada, pues querría que si es factible me mandasen del Museo la colección de Bombus para el mismo mes de Agosto devolverla.

Desde luego ya sé que es una petición atrevida, pero confiando en su bondad y en la de Don Ignacio [Bolívar], y respondiendo en absoluto de todo, es como me atrevo a pedirlo". 24

No hemos podido localizar la respuesta de Dusmet, pero el caso es que la dirección del MNCN accedió a la petición y Quilis pudo disponer de los ejemplares en el verano de 1927, coincidiendo con el tramo final de la redacción del trabajo. ${ }^{25}$

Quilis también procuró entrar en contacto, al margen de las instituciones mencionadas, con naturalistas que le pudieran remitir ejemplares españoles de Bombus. ${ }^{26}$ Uno de los contactados fue el aficionado francés André Seyrig, que por entonces estaba trabajando en las minas de El Soldado (Córdoba), y que escribió a Dusmet en estos términos:

«Tengo todavía aquí media docena de Bombus que estoy reservando para mandarlos directamente al Sr. 
Modesto Quilis de Valencia, que me los ha pedido. Pienso que estará Vd. de acuerdo con esto que me propongo hacer, pues este Sr. me escribió, según decía recomendado por $\mathrm{Vd}$.; no obstante, si lo prefiere, estoy dispuesto a hacer esto por el conducto de V. ${ }^{27}$

La contestación de Dusmet, efectivamente, era para expresar su acuerdo, y de paso ponderar el entusiasmo de que hacía gala Quilis. Y añadía:

"Yo siempre creo que los entomólogos debemos ayudarnos sin reservas y del modo que mejor se sirva a la ciencia». ${ }^{28}$

Este ideal de desinterés y caballerosidad conecta con un sentido de los ejemplares como materiales de acceso comunitario, sin perjuicio de que pudieran integrar colecciones de personas o entidades privadas que mantuvieran sobre aquellos la propiedad, lo cual pone en contraste el proceder de las ciencias que coleccionan con la habitual reserva de los datos en otro tipo de disciplinas (Kohler, 2007). Dusmet se tomaba esto muy en serio, como se ve cuando censuraba el proceder de un aficionado, Fermín Zanón Cervera (1875-1944), conocido de Quilis. Zanón se indignó cuando, tras enviarle unos ejemplares para su clasificación, Dusmet le devolvió solamente una parte, quedándose como es habitual algunos duplicados y compensándole con ejemplares de otras especies. El incidente fue bastante serio, aunque Dusmet finalmente lo disculpara como fruto de la ignorancia de Zanón. ${ }^{29} Y$ es que Dusmet tenía el aval de una dedicación no remunerada a la entomología, compatible, sin embargo, con el máximo rigor científico. Un rigor que le llevó también a formar a su discípulo, lleno de dudas tanto teóricas como prácticas, en cuestiones tan básicas como el concepto de tipo o las autorías de razas y variedades; así se puso de relieve, por ejemplo, al establecer Quilis la nueva especie Dasypoda dusmeti, precisamente dedicada a Dusmet. ${ }^{30}$

A principios de octubre de 1927, Quilis anunciaba a Dusmet que el trabajo de los Bombus ya estaba en imprenta. En él aparecía un agradecimiento especial a Bolívar por autorizar el envío a Valencia de los ejemplares del MNCN (Quilis, 1927, p. 35). Quilis le dedicó la nueva variedad Bombus (Terrestribombus) hortorum bolivari, considerada actualmente sinónima de Bombus (Megabombus) ruderatus ruderatus (Ornosa, Ortiz-Sánchez, 2004, p. 531), a partir de un Ilamativo ejemplar del MNCN. ${ }^{31}$ Poco después enviaba a su mentor, a Bolívar, y a las bibliotecas del MNCN y de la RSEHN, sendas separatas. ${ }^{32}$ Quilis, en todo caso, ya estaba trabajando en otros géneros de ápidos.

\section{LA CONTINUACIÓN DE LOS TRABAJOS SOBRE LOS ÁPIDOS DE ESPAÑA}

A comienzos del otoño de 1927, Quilis comunicó a Dusmet su intención de estudiar los géneros Panurgus y Dasypoda, siempre y cuando el propio Dusmet no estuviera trabajando en ellos, con la intención de publicar un artículo en el Boletín de la RSEHN. ${ }^{33}$ Dos semanas después, Dusmet aún no había contestado, por lo que Quilis le envío una tarjeta postal insistiendo en el asunto. ${ }^{34}$ Dusmet respondió inmediatamente; le daba carta blanca para estudiar los géneros en cuestión y le ofrecía ejemplares y bibliografía. Y añadía:

«Estoy asombrado de lo mucho que trabaja V. No solo ha terminado V. los Bombus, sino que ya ha estudiado Panurgus y Dasypoda, y con éxito y ya en relación con varios notables. ${ }^{35}$

Quilis estaba adquiriendo una creciente autonomía, hasta el punto de que la siguiente carta que envió a Dusmet muestra cómo tomaba la iniciativa de pedirle a Bolívar ejemplares del MNCN. Incluso planteaba a Dusmet el proyecto, "tal vez un poco de ilusión, Vd. juzgará», de reunir en un futuro los estudios de ambos sobre los ápidos españoles en una sola obra. ${ }^{36}$ De humilde continuador de la serie iniciada por Dusmet, se veía ahora compartiendo la autoría de un libro de referencia, aunque volviera a su retórica de la imitación del maestro en la siguiente carta, a la vez que adoptaba cierto tono de experto en temas en los que se sentía legitimado:

«Tiene Vd. en los Bombus cosas muy interesantes, no solo por la especie sino por los lugares en donde los ha cazado, y así he de decirle que son muy interesantes los $B$. soroënsis del Valle de Ordesa, que son los más típicos que he visto". ${ }^{37}$

Dusmet reconocía una gran dificultad en distinguir las diferentes especies de Bombus y le preguntaba a Quilis si había tenido alguna vez dudas con ejemplares que pudieran confundirse con Anthophora. Este le respondió con autoridad de especialista, basándose en su experiencia con más de 3000 ejemplares -«un número corto para estudios de variabilidad pero grande para los de clasificación»-, y aun reconociendo la dificultad que entrañaba el género, decía no creer haber caído en tal confusión, alegando caracteres como la morfología de las patas en las hembras y el aspecto y tamaño del clípeo y el labro en los machos. Además, estaba recibiendo valoraciones positivas de su trabajo por parte de especialistas como Johann Alfken (18621945) y Heinrich Friese (1860-1948). ${ }^{38}$

Sus nuevos objetivos, Dasypoda y Panurgus, lo tenían muy ocupado. ${ }^{39}$ Aunque Dusmet interpretó, tras 
haberle pedido ejemplares, que estaba pensando añadir algunos géneros más (Panurginus, Rophites, etc.) ${ }^{40}$ Quilis le aclaró que esto era solamente por mejorar el conocimiento general de la familia ápidos, pero de ningún modo para ampliar la nómina genérica bajo estudio. ${ }^{41}$ Dusmet aprobó esta actitud: «Bueno es que los vaya conociendo, aunque me parece muy bien que aún no los publique. Conviene ir un poco despacio y no hacer todo a un tiempo». ${ }^{42}$

Tras reunir ejemplares de estudio, ${ }^{43}$ hacia finales de 1927 Quilis declaraba tener el trabajo sobre Dasypoda "casi acabado». ${ }^{44}$ La redacción final, sin embargo, se retrasó a consecuencia del fallecimiento de su padre pocas semanas después. ${ }^{45} \mathrm{~A}$ finales de febrero escribió pidiendo autorización para usar el encabezamiento de "Los Ápidos de España» y seguir la misma organización interna que adoptaba Dusmet en sus trabajos. ${ }^{46}$ Este no tardó en darle su aquiescencia. ${ }^{47}$ Quilis le envió el manuscrito el 15 de marzo y le pidió que se lo entregara a Ignacio Bolívar, diciéndole que deseaba publicarlo en el Boletín. ${ }^{48}$ Al final, sin embargo, se publicó en Eos, la revista especializada en entomología promovida por el propio Bolívar en 1925 como órgano de la Sección de Entomología del MNCN (Bach, Compte, 1997). Según relataba Dusmet, Cándido Bolívar (1897-1976), hijo del anterior y principal responsable de Eos (Casado, Gomis, 1998), aconsejó esta revista porque en el Boletín la publicación se iba a demorar mucho, ${ }^{49}$ aunque sin duda apreció en el trabajo de Quilis el suficiente rigor como para reforzar el perfil especializado de dicha cabecera.

Fuera como fuera, en noviembre aún no había aparecido el artículo, pese a estar las primeras pruebas enviadas cuatro meses antes. ${ }^{50}$ Dusmet había advertido a Quilis de los retrasos habituales que se daban en el MNCN, y de cómo al propio Cándido Bolívar se le acumulaba el trabajo; ${ }^{51}$ en aquella temporada, además, con mayor motivo, pues asistió al 4.ㅇ Congreso Internacional de Entomología, celebrado en agosto en la Universidad de Cornell (Ithaca, Nueva York) (Hose, 1928)..$^{52}$ Finalmente, fue en diciembre cuando apareció el artículo. No tardó Dusmet en hacerle algunas observaciones, centradas en el cálculo de lo que Quilis denominaba «índices de Krüger», un método desarrollado por el entomólogo hamburgués Edgar Krüger (1874-1951) para cuantificar variabilidades fenotípicas (Weidner, 1967, pp. 267-268). Dusmet, en respuesta a una pregunta de Quilis sobre si continuar sus estudios sobre ápidos con Psithyrus o con Panurgus, ${ }^{53}$ aprovechaba para deslizar una serie de críticas en términos algo más fuertes que en ocasiones anteriores:
«Me voy a tomar la libertad de aconsejar a V. que, conteniendo el natural y laudable deseo de publicar muchos trabajos, los repase algo más despacio antes de entregarlos. Digo esto porque, en este de Dasypoda, nos hemos permitido [Cándido] Bolívar y yo retocar algunas frases, que resultaban o largas o con repeticiones. $Y$ he sentido que, en los cuadritos de los índices [...] encuentro que, sin duda por no haberlos

V. repasado, hay indudablemente errores».

Tras aportar ejemplos de tales errores, alababa el esfuerzo mostrado por Quilis y expresaba que su único deseo era "que sus interesantes trabajos carezcan de defectos ${ }^{54}$. Dusmet ya había sido puntilloso con las erratas en el trabajo sobre Bombus, que no obstante disculpó achacándolos a la falta de costumbre con trabajos científicos en las «imprentas de provincias». ${ }^{55}$ Ahora, claramente, subía el nivel de exigencia.

Quilis, que un año antes no vaciló en la autocrítica ante la benevolencia de Dusmet, ${ }^{56}$ respondió con una carta bastante menos dócil. Se abría con un formal «muy señor mío y de mi mayor aprecio», en lugar del cordial "mi muy estimado amigo» que había adoptado en los meses previos. Punto por punto fue replicando a las reconvenciones. En lo que atañía al deseo de publicar, sostenía:

«no trato de producir muchas obras que para nada me sirven, como Vd. comprenderá, y solamente las escribo cuando por suerte tengo tiempo para ello; el año pasado lo tuve y por ello pude dedicarme con alguna mayor libertad al trabajo de Dasypoda, este año probablemente no podré decir lo mismo.

Eso sí, cuando escribo una obra me gusta hacerla lo mejor posible y para ello no omito sacrificio alguno, pues lo mismo me da acostarme a las dos que a las tres de la mañana, si en ese tiempo tengo más tranquilidad y puedo hacerlo mejor».

A continuación, reconocía poder tener defectos de estilo y agradecía «el engorroso trabajo de la corrección» por parte de Bolívar y Dusmet, y señalaba que esperaba unas segundas pruebas que nunca llegaron para completar las correcciones. Finalmente, aclaraba a Dusmet los procedimientos de cálculo de medias aritméticas que había seguido para la estimación de los índices de Krüger, para hacerle ver que los resultados aportados sí eran correctos matemáticamente:

"como comprenderá no tengo la pretensión de ser infalible, especialmente después de haber efectuado cerca de mil mediciones y más de mil operaciones con ellas, que repetidas tres veces por lo menos para su comprobación, son más de tres mil las operaciones efectuadas». 
La reserva de cordialidad la dejó para la despedida, rogándole que le siguiera dando "consejos y advertencias [...] puesto que serán recibidos como de mi mejor y más querido maestro». ${ }^{57}$

Fue posiblemente el desencuentro más fuerte que tuvieron. El «querido maestro» debió de quedar conforme con las explicaciones del discípulo, pues escuetamente le dijo entenderlas y alabó de nuevo la enormidad de su tarea. ${ }^{58}$

La evolución de Quilis desde el trabajo sobre Bombus al de Dasypoda revela una pericia creciente en la tarea de determinación, que culmina con la definición de cuatro nuevas especies de Dasypoda. Una le fue dedicada a Cándido Bolívar y otra a Francisco Morote, director del Instituto de 2. Enseñanza de Valencia y socio activo de la sección de Valencia de la RSEHN (Catalá, 1998). ${ }^{59}$ Otra más lo fue a Dusmet, quien ya era sabedor de ello por una carta del mes de marzo. ${ }^{60}$ Quilis le devolvía así la deferencia de haberle dedicado una especie de Tetralonia cuando aún era un neófito sin obra publicada (Dusmet, 1926, p. 193). En aquel trabajo, Dusmet había homenajeado con nuevas especies a entomólogos reputados como Ignacio Bolívar o Ascensi Codina; y con Quilis no se quedó en el simple agradecimiento por los ejemplares que le había enviado, sino que expresaba con aquella dedicatoria su confianza en aquel «entusiasta entomólogo».

También el nivel de detalle de las ilustraciones, obra del propio Quilis, muy buen dibujante, refuerza esa sensación de madurez acelerada. Y, sobre todo, la incorporación del enfoque cuantitativo ya expuesto pone de relieve un intento de superar la valoración más bien cualitativa de los caracteres diferenciales para la determinación de especies que aún domina en el estudio sobre Bombus, la cual, en buena medida, derivaba de la práctica habitual de Dusmet (Quilis, 1928). Quilis, pues, había optado ya por un modo de trabajo que se apartaba del de su maestro, y halló enseguida reconocimiento por ello, como prueba una carta que Alfken envió a Dusmet y en la que le decía que «ich beglückwünsche Sie, dass Sie einen so fähigen Mitarbeiter gefunden haben». ${ }^{61}$

Pese a las pretensiones expuestas apenas un año antes de iniciar un nuevo estudio sobre el género $P a$ nurgus en España y de dar cima a la vieja aspiración de hacer lo propio con Osmia, ${ }^{62}$ Quilis nunca llegó a publicar nada al respecto. Ya entonces estaba abriendo una nueva línea de trabajo que lo llevó a especializarse en microhimenópteros parasitoides de otras especies de insectos; una investigación muy alejada de los intereses de Dusmet y, por el contrario, plenamente identificada con los de la Estación de Fitopatología Agrícola de Burjassot (Valencia), centro con el que estableció un vínculo laboral que se prolongaría en los años siguientes. De hecho, en la última carta de 1928 le enviaba a Dusmet el manuscrito de un breve trabajo para el volumen de las Memorias de la RSEHN en homenaje a Ignacio Bolívar. El tema era la biología de uno de esos microhimenópteros, Leptomastidea abnormis, que atacaba a un hemíptero, el llamado cotonet (Planococcus citri), que constituía una importante plaga de los naranjos (Quilis, 1929).

No obstante, aún publicó un estudio sobre ápidos años después, el dedicado a los abejorros cucos o Psithyrus, considerados actualmente un subgénero de Bombus. Se trata de unos insectos muy interesantes por cuanto son especies sin castas de obreras cuyas hembras se infiltran en las colonias de abejorros corrientes para subyugarlas, de modo que las obreras de la colonia atacada acaban por cuidar y sacar adelante a las larvas de la invasora. Inicialmente, la idea de Quilis era haber publicado su estudio conjuntamente con el de Bombus, aunque no pudo ser por las prisas de Pardo. ${ }^{63} \mathrm{El}$ artículo de Psithyrus, aun manteniendo los típicos cuadros de determinación y una descripción detallada especie por especie, no seguía la pauta formal de los de Dusmet e incluía como novedad una discusión sobre cuestiones evolutivas (Quilis, 1932). Significativamente, el encabezamiento serial «Los Ápidos de España» tampoco aparecía, marcando la definitiva independencia del discípulo respecto al maestro.

\section{ECONOMÍAS DE LA PRÁCTICA ENTOMOLÓGICA}

En el ensayo que abre el influyente volumen Cultures of natural history, Jardine y Spary (1996) tratan de conformar una tipología de prácticas asociadas al cultivo de la historia natural, según la cual se distinguirían cinco categorías: materiales, sociales, literarias, corporales y reproductivas. La correspondencia entre Dusmet y Quilis nos permite rastrear ese complejo universo, marcado por un énfasis magisterial que manifiesta una práctica reproductiva de transmisión entre generaciones, pero que comporta el resto de niveles, como ya hemos visto en el caso de las prácticas literarias con la supervisión y crítica en la redacción de trabajos.

Todo comienza por la materialidad de la recolección de ejemplares en el campo, condicionada por factores meteorológicos. Desde temporadas estivales poco fructíferas a causa de la sequía, hasta frescos inusuales a finales de la primavera, los vaivenes del tiempo eran frecuente preocupación. ${ }^{64}$ Las excursiones de 
caza de ejemplares, en todo caso, tenían motivaciones que iban más allá de la mera adquisición de material de estudio, implicando lo social y corporal. El sentido deportivo y recreativo se asocia a esa ponderación recurrente del placer (y también de la fatiga) que se asocia a la experiencia del campo, que conlleva "un ejercicio muy saludable, respirando el aire puro de las montañas» (Dusmet, 1944, p. 65). Al mismo tiempo, compartir periplo cazador era un modo de cultivar la amistad. Hasta donde sabemos, Dusmet y Quilis no tuvieron ocasión de salir juntos al campo pese a algunos intentos. ${ }^{65}$ Pasados más de diez años de relación, Quilis insistía en mostrarle cazaderos abundantes en grandes himenópteros en el territorio valenciano, apenas explorado por Dusmet. ${ }^{66}$ De alguna manera, ambos sentían esa falta en su relación científica.

Tras el trabajo de campo, venía la labor de selección y preparación de ejemplares, usualmente condicionada por el exceso de capturas. ${ }^{67}$ Como señala de nuevo Kohler (2007), los científicos coleccionistas no son solamente descubridores, sino también conservadores. Dusmet alabó desde un principio el cuidado que ponía Quilis en la preparación. ${ }^{68}$ Contar con ejemplares duplicados y bien preparados era garantía para establecer relaciones provechosas con otros especialistas, incluidos extranjeros. ${ }^{69}$ La comparación que cualquier estudio taxonómico exige hacía del envío e intercambio una práctica imprescindible y daba fundamento a la comunidad de entomólogos. La primera carta conservada de Dusmet, de enero de 1926, habla de la devolución de dos cajas a Quilis, con 48 ejemplares enviados por este ya clasificados y 63 más aportados por Dusmet. ${ }^{70}$ Empleaban tanto el correo ordinario como los servicios de transporte de empresas, ${ }^{71}$ aparte de la mediación de personas allegadas, como ya hemos visto con Boscá o como fue el caso de Miguel Vila, profesor ayudante del Instituto de Valencia y consocio de Quilis en la sección de Valencia de la RSEHN, desplazado a Madrid para opositar. ${ }^{72}$ No siempre los envíos llegaban en el mejor estado; en una ocasión se rompió la tapa de una caja enviada por Dusmet y se estropearon algunos ejemplares, «aunque afortunadamente ninguno de los de Portugal». Cuando había implicados ejemplares de terceros, como en este caso los remitidos por la Universidad de Coimbra a Dusmet, a su vez reenviados a Quilis para su determinación, la preocupación por el adecuado tránsito de la mercancía era mayor. ${ }^{73} Y$ aunque solía respetarse el ideal caballeresco, a veces sí aparecía el interés económico, como cuando Friese pretendía vender a Quilis unos ejemplares. ${ }^{74}$ Dusmet le aconsejó «andar con tiento, pues es fácil gastar sin relativo provecho». ${ }^{75}$
La circulación de ejemplares conllevaba la tarea fatigosa de gestionar préstamos y devoluciones a particulares e instituciones. Pese a su propósito inicial de hacerlo en agosto de 1927, solamente a finales de octubre pudo Quilis devolver los ejemplares de Bombus a Dusmet y al MNCN. ${ }^{76} \mathrm{El}$ joven no dudada en sincerarse: «iEs una faena tan pesada esta! ${ }^{77}$

La condición de especialista se cimentaba no solamente en las publicaciones, sino también en las determinaciones de ejemplares para las colecciones ajenas, labor lenta y comprometida que interfería en otros aspectos del quehacer del entomólogo, como se pone de relieve a lo largo del epistolario que estudiamos y desde casi los inicios de la relación que nos ocupa. ${ }^{78} \mathrm{La}$ gestión del tiempo era difícil para todos, pero más para el bisoño Quilis, que estaba acabando la carrera de Farmacia como alumno libre por la época del trabajo sobre Bombus. ${ }^{79}$ Su verdadera vocación, sin embargo, lo conducía a la carrera de Ciencias, pues «considero mi sueño dorado el poder ser algún día Doctor en Ciencias Naturales». ${ }^{80}$ Su pretensión era cursarla como alumno oficial, lo que le obligaba a trasladarse a Madrid para la especialidad, mas lo cierto es que la siguió también en régimen libre, acabándola en 1932 e iniciando inmediatamente el doctorado bajo la dirección de Cándido Bolívar. ${ }^{81}$ Dusmet le espoleó y apoyó en la decisión de hacer una segunda licenciatura, aunque le sugería:

«Quizás para sus estudios le perjudique el meterse demasiado en la especialización y en publicar un género tras otro. Sin duda es V. muy vehemente, cosa natural en un joven, pero pudiera serle bueno sujetar su entusiasmo y hacer estudios generales. Me refiero a la parte práctica de la vida, porque si se deja arrastrar por la caza, descripción, etc., será para V. como un vicio. $\rangle^{82}$

Ya hemos visto que Quilis se autoimpuso un ritmo de trabajo de gabinete muy intenso, sobre todo a partir de las investigaciones sobre Dasypoda. Ello preocupaba a Dusmet, que con su recurrente llamada a la prudencia, le advertía sobre sus temores de «si con hacer tan seguidos los trabajos dejará V. las cazas, tan útiles en esa región. Este verano no habrá tenido tiempo». ${ }^{83}$ Quilis respondió reconociendo que había realizado muy pocas capturas, y hacía propósito de que «esto no me sucederá más puesto que en primavera, verano y otoño me dedicaré a la caza activa e insistentemente y en invierno a los estudios»..$^{84}$ En todo caso, Quilis confería a su quehacer entomológico un fin autoformativo cargado de sentido moral:

«Los estudios entomológicos [...] me sirven para modelar mi carácter y adiestrar mi voluntad, ya que en estos estudios el orden y método es el todo y como no les dedico más tiempo del correspondiente, no me estorban. 
No es tampoco mi idea el publicar uno tras otro trabajos entomológicos y si ahora lo hago es tan solo por el corto número de especies de los géneros que estudio. $\nu^{85}$

El ethos científico del joven tenía también mucho de pathos, dimensión esta que se reforzó a partir de 1928, cuando la muerte repentina de su padre le llevó, como primogénito, a tener que sostener a la familia con su trabajo, lo cual frustró su pretensión de estudiar en Madrid. Próximo a licenciarse, recordaba a Dusmet su pesar por no haber podido, a causa de esa circunstancia, "estudiar con mi queridísimo maestro». ${ }^{86}$ Un maestro que, en consonancia con sus convicciones religiosas, le había aconsejado con ocasión del fallecimiento del progenitor, «resignación para soportar esa pena, una de las mayores que ocurren en la vida». ${ }^{87}$

Un aspecto clave del magisterio de Dusmet, que afecta tanto a lo material como a lo moral, se refiere a la iniciación de Quilis en el control de la bibliografía especializada. Este, con gran esfuerzo, empezó pronto a reunir una biblioteca de trabajo bajo la guía de Dusmet. Las cartas de 1926 están llenas de datos que nos muestran hasta qué punto era complicado en la época hacerse con la bibliografía necesaria. Las casas y librerías que distribuían los libros no respondían muchas veces en los plazos esperados, y no quedaba otro recurso que escribir directamente al autor. Así hizo Quilis, por ejemplo, con Schmiedeknecht, autor de una importante monografía sobre los ápidos de Europa (Schmiedeknecht, 1882-1886). Tras no recibir respuesta de la casa Junk de Berlín, recurrió al autor, quien le indicó que podría encontrar sus obras en la librería Friedländer, en la misma capital. ${ }^{88}$ Finalmente:

"La obra de Schmiedeknecht la he adquirido ya, el $1^{\text {er }}$ tomo me costó 15 marcos, está en cuadernillos y falta algo aunque poco. Y la parte del género Osmia también, me costó 5 marcos y faltan 5 o 6 hojas, pero como es muy barato como verá por eso la adquirí [...]. Todo lo más que podré invertir serán unas 350 pts., que es todo el dinero que he podido recoger. iQué caros son los libros y cuánto cuestan de adquirir!"89

El adquirir obras incompletas era, por supuesto, una cuestión de disponibilidad dineraria. Ese libro, completo, costaba 80 marcos. $^{90} \mathrm{Y}$ aunque el contexto de hiperinflación de la República de Weimar ya estaba en trance de superación, las transacciones de este estilo se hacían en marcos-oro y resultaban especialmente onerosas. ${ }^{91}$ La casualidad quiso que, cuando le llegó el libro, Quilis ya estuviera estudiando el género Bombus, siendo precisamente la parte que se ocupaba del mismo la que faltaba. Le pidió entonces a Dusmet que le hiciera el favor de enviarle su ejemplar para copiar dicha parte, a lo cual accedió. ${ }^{92}$

Dusmet trataba de aportar realismo a las pretensiones de aquel novato de «adquirir todas las obras en las que hay descripciones o sinonimias de especies». ${ }^{93} \mathrm{Su}$ experiencia personal no podía ser más esclarecedora:

\footnotetext{
«Cuando vaya V. entrando en faena se asustará de la cuestión de libros. Llevo más de 30 años reuniendo, he comprado mucho, me envían muchos autores, tengo a mano la gran biblioteca de la Sociedad Española y la del Museo y siempre me faltan». ${ }^{94}$
}

Dusmet no se limitaba a aconsejar a Quilis sobre las adquisiciones de bibliografía. Además de regalarle sus propias publicaciones y separatas duplicadas, le enviaba prestadas las obras de otros autores de las que no tenía necesidad inmediata, como hizo con un trabajo de Vogt con ocasión del estudio sobre Bombus. ${ }^{95}$ También le mandó un libro de Friese (1901) para iniciar los trabajos sobre Panurgus y Dasypoda, pues Quilis no había logrado adquirirlo tras varios intentos, incluyendo una petición directa al autor. ${ }^{96}$ Un libro, por cierto, que le decepcionó: «Como Vd. muy bien me ha dicho en otras ocasiones, no debo fiarme de ningún autor por fama de este», aunque asumía que "yo también me equivocaré». ${ }^{97}$ Dusmet le respondió que era normal encontrar defectos en todas las obras, lo que probaba «que la materia es muy difícil» y que la selección de caracteres siempre resultaba problemática..$^{98}$

Es evidente que la carencia de bibliotecas especializadas en Valencia lastraba las posibilidades de Quilis. Aunque la actividad naturalista en la propia ciudad y sus proximidades era apreciable -en parte por las actividades de la sección de Valencia de la RSEHN; en parte por la existencia, precaria pero activa, de centros como el Laboratorio de Hidrobiología y el Museo Paleontológico Municipal-, difícilmente hallarían respuesta las necesidades muy concretas de un himenopterólogo. La posibilidad de futuro para Quilis en Valencia se abrió en un marco institucional alejado, por misión, orientación y localización física, del núcleo más visible de naturalistas locales: la Estación de Fitopatología Agrícola de Burjassot (EFA).

\section{CAMINOS DIVERGENTES BAJO EL SIGNO DE LA AMISTAD}

Ya avanzado 1928, Quilis se incorporó como encargado de los insectarios de multiplicación y del laboratorio de la EFA, después de que esta fuera dotada con 6.000 pesetas de subvención para la lucha biológica contra las plagas del campo, aunque tardó bastantes 
meses en comunicarle a Dusmet el hecho, debido, según decía, a la condición interina del contrato. ${ }^{99}$ Antes, sin embargo, le había hablado de su nuevo mentor, Federico Gómez Clemente (1888-1952), director de la EFA, «que es considerado en el cuerpo [de ingenieros agrónomos] como uno de los mejores componentes», además de ponderar el «magnífico material de laboratorio» que se ponía allí a su disposición. ${ }^{100}$ Parece que Quilis estaba preparando el terreno ante Dusmet, a quien había incluso pedido mediar con el MNCN para la determinación de unos insectos de la EFA. ${ }^{101}$ Quilis también estaría detrás del envío que Gómez Clemente hizo a Dusmet de un folleto publicado por la EFA sobre un agente de control biológico de plagas, en el que el propio Quilis había colaborado. ${ }^{102}$ Era evidente el deseo de seguir manteniendo la reverencia magisterial hacia Dusmet - "sabe puede mandar siempre de su discípulo», se despedirá en una carta ${ }^{103}$, pese a que su nuevo trabajo le llevaba a una línea de investigación muy distinta, centrada en los microhimenópteros de potencial interés agrícola.

El tono general de la relación entre ambos, inevitablemente, cambió. Los envíos mutuos de insectos continuaron, pero el interés de Quilis ya no estaba en los ápidos. Así, le solicitaba referencias de algún especialista en bracónidos - una familia de avispitas parasitoides-, o le inquiría por si había en sus colección particular o en la del MNCN ejemplares de la subfamilia Afidiinae, en la que ahora estaba centrando su atención por ser parasitoides de numerosas especies de pulgones perjudiciales de diferentes cultivos; al tiempo, le confesaba que no podía seguir con el estudio de Panurgus, diferido ya desde hacía mucho tiempo. ${ }^{104}$ Tal vez el sentido de la deuda intelectual contraída le llevara a ofrecer alguna esperanza de un estudio futuro sobre el género; al mismo tiempo, se permitía sugerirle:

"¿Por qué no coge ahora el género Osmia? Es uno de los que más me han gustado y del que le podría mandar material algo abundante. Aparte, creo en la existencia de una buena cantidad de cosas nuevas y mucho raro». ${ }^{105}$

Dusmet no se pronunció inicialmente ante la propuesta, y de hecho no publicó trabajo alguno sobre ese género. Seguramente, tras desearle cariñosamente «mucho éxito en sus pequeños» ${ }^{106}$, ya se había resignado a que aquel discípulo que tan buena disposición mostrara a continuar su propia línea optara por otra empresa científica, la del estudio de aquellos microhimenópteros tan distintos de los llamativos ápidos a los que habían consagrado, uno y otro, tantos esfuerzos. Y por mucho que le expresara su alegría porque «esté V. en ese puesto, agradable para V. y en el cual hará V. excelentes servicios a la Agricultura nacional», ${ }^{107}$ el deje de frustración es patente en la carta a otro valenciano, el ex-militar y naturalista Manuel Vidal (1885-1959): «mucho me alegraré de que V. se fije en los himenópteros. Casi ya no hay nadie más que yo, pues se han ido pasando a los microhimenópteros» ${ }^{108}$.

Las cartas se fueron espaciando; así lo lamentaba Quilis en 1931, quien seguía insistiendo en que Dusmet debía estudiar el género Osmia, «el que más me gustó y el sueño dorado de mi afición apidológica» ${ }^{109}$. El ofrecimiento fue ahora abiertamente rechazado, pues si Dusmet expresaba haber leído la carta de Quilis «con sentimiento, al ver que decididamente no puede ocuparse más que de sus pequeños», también reconocía estar demasiado ocupado con su hacienda en Ambel, donde cada vez pasaba más tiempo y «en donde apenas puedo hacer nada por falta de libros». ${ }^{110}$ Hasta de "peligros personales» hablará más adelante, quejándose veladamente de las consecuencias de la nueva legislación republicana, pero, sobre todo, de «haber perdido su útil colaboración». ${ }^{111}$ Quilis negó esto último: «de ninguna manera ha perdido un colaborador (diga mejor un discípulo)», pues «también cazo [himenópteros] grandes que poco a poco iré mandando a Vd.» ${ }^{112}$ Los intereses de estudio se habían distanciado; pero el vínculo a través de la captura de ejemplares destinados a la otra parte permitía mantener una identidad cultural (Kohler, 2007), que a su vez evitaba la ruptura emocional.

El 1. de mayo de 1935, Modesto Quilis felicitaba como era su costumbre a José María Dusmet por su onomástica, con un evidente retraso de más de cuarenta días. Aquella misiva, escrita en papel timbrado con el membrete del Instituto Nacional de 2.a Enseñanza «Blasco Ibáñez» de Valencia, donde Quilis era profesor desde finales de $1933,{ }^{113}$ contenía una grave noticia que justificaba la dilación referida: a finales de marzo, había sido intervenido quirúrgicamente para serle extirpado un riñón. El postoperatorio había transcurrido felizmente y Quilis se sentía ya con el impulso suficiente como para anunciar a quien seguía considerando su maestro que esperaba poder saludarlo en el inminente congreso internacional de entomología que iba a tener lugar en Madrid. ${ }^{114} \mathrm{Y}$ así fue, como acredita una carta de 1936. Quilis refería que le había sido encomendado un estudio sobre microhimenópteros fósiles de Alsacia, enviados por un conocido de Lucien Berland (1888-1962), entomólogo a quien había sido presentado durante el Congreso por el propio Dusmet. También 
elogiaba el reciente trabajo de Dusmet (1935a), una suerte de combinación entre memorias de una vida de ciencia y guía para noveles publicada en las Memorias de la SEE. ${ }^{115}$ Dusmet le contestó diciendo que «lo único de que tengo vanidad es la afición al trabajo, que no es muy frecuente en los españoles», y le enviaba también una separata de su reciente artículo sobre la subfamilia Panurginae (Dusmet, 1935b), en la que se encuadraba Panurgus, ese género que Quilis había acabado por abandonar. ${ }^{116}$ Poco después, acusaba éste recibo, ponderando una vez más la excelencia de dicho trabajo de Dusmet, que «me parece admirable pues yo ya conozco lo difícil que es este grupo». ${ }^{117}$

Este fue el final de su intercambio epistolar. Tras estallar la Guerra Civil, un entomólogo italiano, el barone Francesco Biegeleben (1881-1942), de Appiano, escribió a Dusmet preguntando por los colegas españoles, incluido Quilis. ${ }^{118}$ Dusmet, que se encontraba en Ambel, en zona sublevada, le dijo que nada sabía. ${ }^{119}$ Ya acabada la contienda, el barone volvió a interesarse por el «egregio signore M. Quilis». ${ }^{120}$ Dusmet ya era desde hacía un mes sabedor de la muerte de su discípulo a causa de su dolencia renal. ${ }^{121} \mathrm{El}$ deceso había acontecido el 3 de enero de 1938 (Gómez Clemente, 1940).

Dusmet aún prestaría dos servicios a la memoria de su discípulo. Uno fue la redacción de una necrológica para la RSEHN, en la que lo definía como «buen amigo y excelente investigador» (Dusmet, 1942, p. 34). Para la misma, solicitó información a la familia de Quilis. Respondió su hermano Ricardo, contratado para seguir su labor en la EFA, quien envió a Dusmet «un resumen de los hechos más destacados de su vida». ${ }^{122}$ El otro servicio consistió en dar a la imprenta, con carácter póstumo, los tres últimos trabajos de Quilis. Uno de ellos, relativo a los fósiles alsacianos, salió en Eos (Quilis, 1940a), revista de la cual el propio Dusmet había pasado a ocupar la dirección. Los otros dos correspondían a las comunicaciones presentadas en el VI Congreso Internacional de Entomología (Quilis, 1940b, 1940c). Dusmet, efectivamente, había sido nombrado miembro de la comisión que debía proceder a la publicación de las actas del Congreso. ${ }^{123} \mathrm{Su}$ leal proceder con Quilis contrasta vivamente con la acción censora, forzada tal vez por las circunstancias, que ejerció con los trabajos de Ignacio y Cándido Bolívar y de otros entomólogos desafectos con el nuevo régimen, en lo que supuso un triste ejemplo de represalia, tanto más lamentable cuanto que se ejerció contra personas que, pese a las diferencias ideológicas, tan próximas habían estado a Dusmet en la labor científica (Gomis, 2014; Puig-Samper, 2016).

\section{CONCLUSIÓN}

En su hermoso ensayo Lecciones de los maestros, George Steiner (2004) hace memoria de la tensión entre considerar el sentido del magisterio como la imitación del acto trascendente de descubrir, frente al enfoque que prima la vertiente ejemplarizante que debe presidir el quehacer del que enseña. No cabe duda de que Quilis optó por una mímesis del proceder de Dusmet que acabó por conducirle, sin embargo, a una línea propia e independiente de investigación parcialmente impuesta por las circunstancias materiales de la vida. Quilis abandonó el estudio de los ápidos y así cesó aquella imitación, pero mantuvo la referencia ejemplar de Dusmet en un renovado ejercicio de reconocimiento hacia quien le había iniciado. Con la adopción de un compromiso vital por la entomología, directamente ligado a una actitud de superación y a una ética del esfuerzo, Quilis correspondió a su maestro. Dusmet, por su parte, asumió ante Quilis un compromiso magisterial basado en la reivindicación activa de la ayuda mutua y el intercambio de ejemplares de estudio en el seno de las comunidades de entomólogos, al que siguió, tras el alejamiento de las respectivas líneas de investigación, una expresión sincera de amistad pese a la distancia física y la diferencia de edad. En el camino de socialización científica que transitó Quilis de la mano de Dusmet encontramos un buen ejemplo de cómo las emociones importan al estudiar el quehacer científico (Alberti, 2009; Dror, 2009). Y aunque buena parte del magisterio de Dusmet se sustanció en ofrecer una guía práctica a aquel entomólogo novel en forma de sugerencias bibliográficas, correcciones estilísticas, llamadas a la prudencia, consejos para el campo y aclaraciones taxonómicas, la relación establecida a través de las cartas se reveló también como ámbito para el cultivo de un sentimiento mutuo de aprecio y admiración.

\section{AGRADECIMIENTOS}

Al personal del archivo y la biblioteca del Museo Nacional de Ciencias Naturales por las facilidades prestadas para la consulta de los fondos. A la familia Quilis Llopis por facilitarme el acceso a la documentación de su archivo particular. A María y Jaime Lambea y a Teo Alonso-Pesquera por sus noticias y materiales sobre Dusmet, y a Manuel Gracia, del Centro de Estudios Borjanos, por ponerme en contacto con los descendientes del ilustre entomólogo de Ambel. Este trabajo está financiado por el proyecto FUSPBS-PPC27/2015, de la Fundación Universitaria San Pablo CEU. 


\section{NOTAS}

1. [Apuntes biográficos mecanografiados sobre José María Dusmet]. Sin fecha. Archivo del Museo Nacional de Ciencias Naturales (ACN), P51. No hay biografías de referencia sobre Dusmet, aunque sí dos notas necrológicas (Ceballos 1960, 1962-1963) y sendos esbozos en Martín Albaladejo (2000, p. 287), Martín Albaladejo (2005) y Martínez Tejero (2005, p. 143), además de una entrada en la Gran Enciclopedia Aragonesa: Anónimo (2000), “Dusmet y Alonso, José María". En: Gran Enciclopedia Aragonesa [en línea], disponible en: http://www.enciclopedia-aragonesa.com/ voz.asp?voz_id=4826\&tipo_busqueda $=1 \&$ nombre $=$ dus met\&categoria_id=\&subcategoria_id=\&conlmagenes= [consultado el 6-6-2016].

2. Las correspondencia conservada muestra cómo Dusmet asesoró a otros entomólogos y naturalistas, como José Giner, Fermín Zanón, etc., relaciones que esperamos poder estudiar en breve.

3. Por años, la distribución de cartas es la siguiente: 1925: Quilis 4 cartas, Dusmet 0 cartas; 1926: Q 6, D 4; 1927: Q 19, D 12; 1928: Q 9, D 8; 1929: Q 7, D 5; 1930: Q 5, D 5; 1931: Q 2, D 2; 1932: Q 3, Q 2; 1933: Q 1, D 2; 1934: Q 1, D 0; 1935: Q 1, D 0; 1936: Q 2, D 1. Las cartas están en el Fondo "Personal Científico» $(P)$, Sección «José M.a Dusmet». En cada caso citaremos la signatura de caja con el número de expediente y número de documento dentro del expediente.

4. Quilis a Dusmet. V, 10-1-1925. ACNP53/001/005.

5. Con seguridad, se trata de Gaulle (1908).

6. Quilis a Dusmet. V, 18-1-1925. ACNP53/001/009.

7. Quilis a Dusmet. V, 22-12-1925. ACNP53/001/059.

8. Quilis a Dusmet. V, 9-1-1927. ACNP52/001/005. En el original figura el año 1926, pero la lectura cruzada con otras cartas del fondo no deja lugar a la duda de que es el típico error de arrastrar el año anterior en las fechas de comienzo de año.

9. Quilis a Dusmet. V, 22-10-1926. ACNP53/002/132. El trabajo al que se refiere Quilis es Dusmet (1926). Por «Macrocera», tal como lo usa Quilis en su carta, hay que entender el género Tetralonia. El nombre Macrocera se reconocía ya entonces solamente válido para un género de dípteros, aunque era todavía más o menos informalmente aplicado a varias especies de ápidos.

10. Quilis a Dusmet. V, 16-12-1926. ACNP53/001/059.

11. Quilis a Dusmet. V, 20-11-1926. ACNP53/002/160.

12. Quilis a Dusmet. V, 20-12-1926. ACNP53/001/115.

13. Quilis a Dusmet. V, 18-6-1926. ACNP53/002/097.
14. Quilis a Dusmet. V, 22-10-1926. ACNP53/002/132.

15. Dusmet a Quilis. M, 24-10-1926. ACNP53/002/133.

16. Quilis a Dusmet. V, 16-12-1926. ACNP53/001/059.

17. Dusmet a Quilis. M, 18-12-1926. ACNP53/002/189; M, 131-1927. ACNP53/003/011.

18. Quilis a Dusmet. V, 3-1-1927. ACNP53/001/059. En el original figura el año 1926, pero la lectura cruzada con otras cartas del fondo no deja lugar a la duda de que es el típico error de arrastrar el año anterior en las fechas de comienzo de año.

19. Dusmet a Quilis. M, 7-1-1927. P53/003/001. Dusmet a Vogt. M, 10-1-1927. ACNP53/003/002.

20. Dusmet a Lorente de Nó. M, 3-2-1927. ACNP53/003/040.

21. Dusmet a Quilis. M, 13-1-1927. ACNP53/003/011.

22. Quilis a Dusmet. V, 18-1-27. ACNP53/003/018. En todo caso, Quilis visitó el MCNB en septiembre; Codina a Dusmet. B, 8-11-27. ACNP53/003/187.

23. Quilis a Dusmet. V, 29-1-27. ACNP53/003/034.

24. Quilis a Dusmet. V, 29-1-27. ACNP53/003/034.

25. Quilis a Dusmet. V, 5-10-27. ACNP53/003/160.

26. Quilis a Dusmet. V, 18-7-27. ACNP53/003/153.

27. Seyrig a Dusmet. El Soldado (Córdoba), 21-4-27. ACNP53/003/110.

28. Dusmet a Seyrig. [M,] 24-4-27. ACNP53/003/113.

29. Dusmet a Quilis. [M,], 25-3-30. ACNP54/002/067.

30. Quilis a Dusmet. V, 18-7-27. P53/003/153; V, 24-1027. P53/003/168. Dusmet a Quilis. [M], 29-10-27. ACNP53/003/172.

31. Quilis a Dusmet. V, 5-10-27. ACNP53/003/160. Dusmet a Quilis. [M], 22-10-27. ACNP53/003/166. Podría extrañar que el primer taxón descrito por Quilis no fuera dedicado a Dusmet; en todo caso, pesaría la posición de gran autoridad de Bolívar y el hecho objetivo de haber prestado como director del MNCN tantas facilidades a un entomólogo novel como Quilis.

32. Quilis a Dusmet. V, 7-11-27. ACNP52/002/069.

33. Quilis a Dusmet. V, 5-10-27. ACNP53/003/160.

34. Quilis a Dusmet. V, 21-10-27. ACNP52/002/064 
35. Dusmet a Quilis. [M], 22-10-27. ACNP53/003/166.

36. Quilis a Dusmet. V, 24-10-1927. ACNP53/003/168.

37. Quilis a Dusmet. V, 31-10-1927. ACNP53/003/169.

38. Quilis a Dusmet. V, 25-11-27. ACNP52/003/203bis. Quilis a Dusmet. V, 8-12-27. ACNP52/002/084.

39. Quilis a Dusmet. V, 7-11-27. ACNP52/002/069.

40. Quilis a Dusmet. V, 31-10-1927. ACNP53/003/169. Dusmet a Quilis. M, 7-11-27. ACNP53/003/208.

41. Quilis a Dusmet. V, 11-11-27. ACNP53/003/188.

42. Dusmet a Quilis. [M], 22-11-27. ACNP53/003/200.

43. Quilis a Dusmet. V, 25-11-27. ACNP52/003/203bis.

44. Quilis a Dusmet. V, 22-12-27. ACNP53/003/225.

45. Quilis a Dusmet. V, 22-2-28. ACNP53/003/060.

46. Quilis a Dusmet. V, 28-2-28. ACNP53/004/040.

47. Dusmet a Quilis. M, 1-3-28. ACNP53/003/069.

48. Quilis a Dusmet. V, 15-3-28. ACNP53/003/076.

49. Dusmet a Quilis. [M,] 28-3-28. ACNP53/003/088.

50. Quilis a Dusmet. V, 6-11-28. ACNP53/003/169. Dusmet a Quilis. M, 24-5-28. ACNP53/003/130.

51. Dusmet a Quilis. M, 2-4-28. ACNP53/003/095.

52. Dusmet a Quilis. [M,] 12-11-28. ACNP53/003/189.

53. Quilis a Dusmet. V, 14-12-28. ACNP53/004/203.

54. Dusmet a Quilis. M, 25-12-28. ACNP53/003/227.

55. Dusmet a Quilis. [M,] 10-11-1927. ACNP53/003/177.

56. Quilis a Dusmet. V, 13-11-1927. ACNP52/002/074; V, 2212-27. ACNP53/003/225.

57. Quilis a Dusmet. V, 29-12-28. ACNP53/004/214.

58. Dusmet a Quilis. [M,] 8-1-29. ACNP54/001/010.

59. Dusmet corrigió a su discípulo en cuestiones de nomenclatura con ocasión de esta especie. En su manuscrito, Quilis había establecido el epíteto específico morotesi, pero las normas indicaban añadir una simple i a los apellidos para formar el genitivo, de modo que debía ser morotei. Dusmet a Quilis. [M,] 28-3-28. ACNP53/003/088.

60. Quilis a Dusmet. V, 15-3-28. ACNP53/003/076.
61. "Le felicito por haber encontrado un colaborador tan capacitado». Alfken a Dusmet. Brema, 23-1-29. ACNP54/001/022.

62. Quilis a Dusmet. V, 20-11-1927. P53/003/196. Quilis a Dusmet. V, 22-12-27. ACNP53/003/225.

63. Quilis a Dusmet. V, 31-10-1927. ACNP53/003/169.

64. Quilis a Dusmet. V, 22-10-1926. ACNP53/002/132. Quilis a Dusmet. Burjassot, 27-6-29. ACNP54/001/140.

65. Quilis a Dusmet. Burjassot, 9-4-33. ACNP55/carpeta1933. Dusmet a Quilis. M, 24-4-33. ACNP55/carpeta1933. Los cuadernos de excursiones de Dusmet tampoco citan la presencia de Quilis; ACN0347/010.

66. Quilis a Dusmet. Burjassot, 18-2-36. ACNP53/002/021.

67. Quilis a Dusmet. V, 18-6-1926. ACNP53/002/097.

68. Dusmet a Quilis. [M,] 21-3-1926. ACNP53/002/096.

69. Dusmet a Quilis. [M,] 11-12-27. ACNP53/003/215.

70. Dusmet a Quilis. [M,] 14-1-1926. ACNP53/002/008.

71. Dusmet a Quilis. M, 13-1-1927. ACNP53/003/011.

72. Quilis a Dusmet. V, 18-3-1926. ACNP53/002/044. Lista (1926), "Lista de socios de la Española de Historia Natural en 13 de enero de 1926", Boletín de la Real Sociedad Española de Historia Natural, 26, pp. 9-34.

73. Quilis a Dusmet. Burjassot, 3-3-31. ACNP54/003/047. Dusmet a Quilis. [M,] 2-3-31. ACNP54/002/046.

74. Quilis a Dusmet. V, 8-12-27. ACNP52/002/084.

75. Dusmet a Quilis. [M,] 11-12-27. ACNP53/003/215.

76. Quilis a Dusmet. V, 31-10-1927. ACNP53/003/169.

77. Quilis a Dusmet. V, 24-10-1927. ACNP53/003/168.

78. Dusmet a Quilis. [M,] 21-3-1926. ACNP53/002/096.

79. Dusmet a Marcet, carta incompleta. [M,] 28-2-1927. ACNP52/003/012.

80. Quilis a Dusmet. V, 25-11-27. ACNP52/003/203bis.

81. Quilis a Dusmet. Burjassot, 9-4-33. ACNP55/carpeta1933. Hay que recordar que Dusmet no ocupaba ningún puesto oficial, lo que dificultaría que pudiera dirigir formalmente una tesis. En todo caso, parece ser que Quilis no completó su doctorado, pues no figura el mismo en su expediente personal como profesor auxiliar de la Universidad de Valencia; «Expediente personal de D. Modesto Quilis Pérez», AUV1364/10. La elección de Cándido Bolívar como director pudo haber estado motivada por la reorientación del 
trabajo de Quilis hacia los microhimenópteros. La escasa correspondencia entre ambos que se ha conservado nada dice al respecto, en todo caso.

82. Dusmet a Quilis. [M,] 11-12-27. ACNP53/003/215.

83. Dusmet a Quilis. [M,] 10-11-1927. ACNP53/003/177.

84. Quilis a Dusmet. V, 13-11-1927. ACNP52/002/074.

85. Quilis a Dusmet. V, 16-12-27. ACNP53/003/223.

86. Quilis a Dusmet. Burjassot, 3-3-31. ACNP54/003/047

87. Dusmet a Quilis. M, 24-2-28. ACNP53/003/063.

88. Quilis a Dusmet. V, 20-11-1926. ACNP53/002/160.

89. Quilis a Dusmet. V, 9-1-1927. ACNP52/001/005. También en esta aparece, erróneamente, el año de 1926.

90. Dusmet a Quilis. M, 24-10-1926. ACNP53/002/133.

91. Quilis a Dusmet. V, 20-12-1926. ACNP53/001/115.

92. Quilis a Dusmet. V, 22-2-1927. ACNP53/003/061. Dusmet a Quilis. M, 26-2-27. ACNP53/003/003. Quilis a Dusmet. V, 6-3-1927. ACNP52/002/017. El ejemplar de Quilis, con las páginas faltantes manuscritas, se conserva en el Instituto Valenciano de Investigaciones Agrarias.

93. Quilis a Dusmet. V, 16-12-1926. ACNP53/001/059.

94. Dusmet a Quilis. M, 18-12-1926. ACNP53/002/189.

95. Dusmet a Quilis. M, 7-1-27. ACNP53/003/001.

96. Dusmet a Quilis. [M,] 11-12-27. ACNP53/003/215. Quilis a Dusmet. V, 8-12-27. ACNP52/002/084.

97. Quilis a Dusmet. V, 16-12-27. ACNP53/003/223.

98. Dusmet a Quilis. [M,] 27-12-27. ACNP53/003/228.

99. Trabajos (1928), "Trabajos de las Estaciones de Fitopatología Agrícola. Estación de Fitopatología Agrícola de Valencia", Boletín de Patología Vegetal y Entomología Agrícola, 3, pp. 57-58, 189-193. Quilis a Dusmet. Burjassot, 10-5-29. ACNP54/001/110.

100. Quilis a Dusmet. Burjassot, 16-4-29. ACNP54/001/089.

101. Quilis a Dusmet. Burjassot, 22-2-29. ACNP54/001/047. Dusmet a Quilis. M, 26-2-29. ACNP54/001/052.
102. Gómez Clemente a Dusmet. Burjassot, 13-4-29. ACNP54/001/088. Dusmet a Gómez Clemente. M, 21-429. ACNP54/001/097.

103. Quilis a Dusmet. Burjassot, 16-4-29. ACNP54/001/089.

104. Quilis a Dusmet. Burjassot, 10-5-29. ACNP54/001/110. Burjassot, 17-2-30. ACNP54/002/043.

105. Quilis a Dusmet. Burjassot, 3-7-30. ACNP54/002/162.

106. Dusmet a Quilis. [M,] 25-3-30. ACNP54/002/067.

107. Dusmet a Quilis. [M,] 5-5-29. ACNP54/001/104.

108. Dusmet a Vidal. [M,] 10-9-31. ACNP54/003/140.

109. Quilis a Dusmet. Burjassot, 24-2-31. ACNP54/003/041. Subrayado en el original.

110. Dusmet a Quilis. [M,] 2-3-31. ACNP54/002/046.

111. Dusmet a Quilis. [M,] 14-3-32. ACNP54/004/042.

112. Quilis a Dusmet. Burjassot, 17-3-32. ACNP54/004/048.

113. Quilis a Cándido Bolívar. V, 7-11-33. ACN0440/001.

114. Quilis a Dusmet. V, 1-5-35. ACNP53/001/026.

115. Quilis a Dusmet. Burjassot, 18-2-36. ACNP53/002/021.

116. Dusmet a Quilis. [M,] 22-2-36. ACNP53/002/026.

117. Quilis a Dusmet. Burjassot, 27-2-36. ACNP53/002/025.

118. Biegeleben a Dusmet. Appiano, 23-3-37. ACNP55/Carpeta 1936-1939.

119. Dusmet a Biegeleben. Ambel, 18-5-37. ACNP55/Carpeta 1936-1939.

120. Biegeleben a Dusmet. Appiano, 16-5-39. ACNP55/Carpeta 1936-1939.

121. Dusmet a Biegeleben. [M,] 4-6-39. ACNP55/Carpeta 1936-1939.

122. Ricardo Quilis a Dusmet. Burjassot, 27-5-41. ACNP55/Legajo 2. [Resumen biográfico de Modesto Quilis, atribuido a su hermano Ricardo]. Copia mecanografiada. ACNP51.

123. Ministerio de Educación Nacional. Subsecretaría. Oficio 166. 17-1-1940. ACNP55/Legajo 1. 


\section{BIBLIOGRAFÍA}

Aguilar, Jacques d' (2006), Histoire de l'entomologie, Paris, Delachaux \& Niestlé.

Alberti, Fay Bound (2009), "Bodies, Hearts and Minds: Why Emotions Matter to Historians of Science and Medicine", Isis, 100, pp. 798-810.

Bach, Carmen; Compte, Arturo (1997), “La entomología moderna en España. Su desarrollo: de los orígenes a 1960", Boletín de la Sociedad Entomológica de Aragón, 20, pp. 367-392.

Baratas, Alfredo (2010), "Neuronas, hormonas y genes: la investigación biológica en la Junta para Ampliación de Estudios". En: Sánchez Ron, José Manuel; García-Velasco, José (ed.), 100 JAE. La Junta para Ampliación de Estudios e Investigaciones Científicas en su Centenario. Tomo I, Madrid, Fundación Francisco Giner de los Ríos/Residencia de Estudiantes, pp. 583-597.

Boer, Arnold de (2004), "Oskar Vogt en zijn entomologische collecties, of: het verband tussen hommels en hersenonderzoek", Entomologische Berichten, 64 (2), pp. 62-68.

Camarasa, Josep Maria; Catalá, Jesús I. (2007), Els nostres naturalistes, València, Publicacions de la Universitat de València.

Camarasa, Josep Maria; Vidal, Josep Manel (coord.) (2006), "Dossier. Correspondència entre científics i història de la ciencia", Afers, 21 (53/54), pp. 9-134.

Casado, Santos (1997), Los primeros pasos de la ecología en España, Madrid: Ministerio de Agricultura, Pesca y Alimentación / Residencia de Estudiantes.

Casado, Santos (2006a), "Ignacio Bolívar y la modernización de la historia natural en la Junta", Boletín de la Institución Libre de Enseñanza, 63-64, pp. 189-205.

Casado, Santos (2006b), “Celso Arévalo-Luis Pardo. La introducció d'una disciplina", Afers, 21 (53/54), pp. 87-98.

Casado, Santos; Gomis, Alberto (1998), “Cándido Bolívar (18971976). Apuntes para una biografía pendiente", Boletín de la Institución Libre de Enseñanza, 31, pp. 51-67.

Catalá, Jesús I. (1998), “La sección de Valencia de la Real Sociedad Española de Historia Natural (1913-1936)". En Memorias de la Real Sociedad Española de Historia Natural, Tomo 1 (2.. época), pp. 47-63.

Catalá, Jesús I. (2003a), "L'estudi històric de les societats naturalistes en contexts locals: el cas valencià dins el cas espanyol", Butlletí de la Institució Catalana d'Història Natural, 71, pp. 5-20.

Catalá, Jesús I. (2003b), “Confessionalitat i laïcisme: La fundació de l'Asociación Española para el Progreso de las Ciencias", Afers, 18 (46), pp. 565-590.

Catalá, Jesús I.; Azkárraga, José María (2015), “La història natural a I'Institut Lluís Vives a l'inici del segle XX", Futura, 30, pp. 26-29.
Catalá, Jesús I.; Guillem, Ximo (2006), “Control de plagas y desarrollo institucional en la Estación de Patología Vegetal de Burjassot (Valencia) (1924-1931)", Asclepio, 58, pp. 249-280.

Ceballos, Gonzalo (1960). “In memoriam. Excmo. Sr. D. José María Dusmet y Alonso 1869-1960”, Eos, 36, pp. 387-388.

Ceballos, Gonzalo (1962-1963). “In memoriam. Excmo. Sr. D. José María Dusmet y Alonso (1869-1960)", Boletín de Patología Vegetal y Entomología Agrícola, 26, pp. 299-300.

Chapman, R.F. (2000), "Entomology in the Twentieth Century", Annual Review of Entomology, 45, pp. 261-285.

Compte, Arturo (1988), "La J.A.E. y la investigación zoológica en España”. En: Sánchez Ron, José Manuel (coord.), 1907-1987. La Junta para Ampliación de Estudios e Investigaciones Científicas 80 años después. Simposio Internacional, vol. 2, Madrid, C.S.I.C., pp. 429-464.

Dror, Otniel E. (2009), "Afterword: A Reflection on Feelings and the History of Science", Isis, 100, pp. 848-851.

Dusmet, José María (1926), "Los ápidos de España. VII. Géneros EUCERA Scop. y TETRALONIA Spin.". En Memorias de la Real Sociedad Española de Historia Natural, Tomo 13, pp. 83-201.

Dusmet, José María (1935a), “Cuarenta y cinco años en busca de Himenópteros de España. Excursiones, consejos y resultados". En Memorias de la Sociedad Entomológica de España, vol. 4, pp. 1-116

Dusmet, José María (1935b), “Los Ápidos de España. VIII. Subfamilia PANURGINOS”, Eos, 11, pp. 117-172.

Dusmet, José María (1942), "Don Modesto Quilis Pérez", Boletín de la Real Sociedad Española de Historia Natural, 40, pp. 33-35.

Dusmet, José María (1944), Recuerdos para contribuir a la historia de la entomología de España. Discurso leído en el acto de su recepción por el Excmo. Sr. D.... y contestación del Excmo. Sr. D. Eduardo Hernández-Pacheco el día 21 de junio de 1944, Madrid, Real Academia de Ciencias Exactas, Físicas y Naturales.

Friese, Heinrich (1901), Die Bienen Europa's (Apidae Europaeae) nach ihren Gattungen, Arten und Varietäten. Theil 6. Solitäre Apiden, Innsbruck, Lampe.

Gaulle, Jules de (1908), Catalogue systématique et biologique des hyménoptères de France, Paris, Librairie Paul Klincksieck.

Gómez Clemente, Federico (1940), “Modesto Quilis (19041938)", Boletín de Patología Vegetal y Entomología Agrícola, 9, 306-308.

Gomis, Alberto (2014), “Mimbres para otro cesto: De la Sección de Entomología del Museo Nacional de Ciencias Naturales al 
Instituto Español de Entomología", Boletín de la Real Sociedad Española de Historia Natural, sección Biológica, 108, 37-47.

Hagen, K.S.; Franz, J.M. (1973), "A history of biological control”. En: Smith, R.F.; Mittler, T.M.; Smith, C.N. (ed.), History of entomology, Palo Alto, Annual Reviews/Entomological Society of America, pp. 433-476.

Hose, Charles (1928), "Report of the Fourth International Congress of Entomology", Empire Forestry Journal, 7 (2), pp. 262-270.

Jardine, Nicholas; Spary, Emma (1996), "The natures of cultural history". En: Jardine, Nicholas; Secord, James A.; Spary, Emma (ed.), Cultures of natural history, Cambridge, Cambridge University Press, pp. 3-13.

Kohler, Robert E. (2006), All Creatures: Naturalists, Collectors, and Biodiversity, 1850-1950, Princeton, Princeton University Press.

Kohler, Robert E. (2007), “Finders, Keepers: Collecting Sciences and Collecting Practice", History of Science, 45, pp. 428-454.

Jones, D. Price (1973), "Agricultural entomology”. En: Smith, R.F.; Mittler, T.M.; Smith, C.N. (ed.), History of entomology, Palo Alto, Annual Reviews/Entomological Society of America, pp. 307-332.

Martín Albaladejo, Carolina (2000), "Tendencias de la Taxonomía entomológica española", Universidad Complutense de Madrid, tesis doctoral.

Martín Albaladejo, Carolina (2005), Bibliografía entomológica de autores españoles (1758-2000), Madrid, Museo Nacional de Ciencias Naturales-CSIC, CD-ROM.

Martínez Tejero, Vicente (2005), Piedras, fósiles, plantas, insectos, peces, pájaros... Naturalistas aragoneses, Zaragoza, Biblioteca Aragonesa de Cultura.

Ornosa, Concepción; Ortiz-Sánchez, Francisco Javier (2004), Hymenoptera, Apoidea I. En: Ramos, María Ángeles (ed.), Fauna Ibérica, vol. 23, Madrid, Museo Nacional de Ciencias Naturales-CSIC, 556 pp.

Pelayo, Francisco (2006), “Pehr Löfling-Carl von Linné. Deixeble i mestre", Afers, 21 (53/54), pp. 51-56.

Puig-Samper, Miguel Ángel (2016), Ignacio Bolívar Urrutia. Patriarca de las Ciencias Naturales en España y fundador de la revista Ciencia en México. Discurso leído ante la Academia Mexicana de Ciencias para su recepción como miembro correspondiente, Ciudad de México, Doce Calles / Academia Mexicana de Ciencias.

Quilis Pérez, Modesto (1927), “Los Ápidos de España. Género BOMBUS Latr.", Anales del Instituto Nacional de 2.믈eñanza de Valencia, 15 (66), 121 pp.

Quilis Pérez, Modesto (1928), "Los Ápidos de España. Estudio monográfico de las Dasypoda Latr.", Eos, 4, pp. 173-241.
Quilis Pérez, Modesto (1929), "Biología del calcídido Leptomastidea abnormis (Girault), parásito del Pseudococcus citri Risso". En Memorias de la Real Sociedad Española de Historia Natural, Tomo 15, pp. 73-80.

Quilis Pérez, Modesto (1932), "Los Psithyrus españoles (Hym. Apid.)", Eos, 8, pp. 185-222.

Quilis Pérez, Modesto (1940a), "Los Aphidiidae fósiles de Witthenheim (Haut-Rhin, Francia)(Hym. Brac.)”, Eos, 14, pp. 23-61.

Quilis Pérez, Modesto (1940b), "Cálculo de las fajas isocondicionales y de las líneas del máximo desarrollo para los insectos". En: VI Congreso Internacional de Entomología. Madrid, 6-12 septiembre de 1935, Madrid, Laboratorio de Entomología del Museo Nacional de Ciencias Naturales, vol. 2, 447-454.

Quilis Pérez, Modesto (1940c), "Influencia de los factores climáticos en el cálculo de los ciclos biológicos de los insectos". VI Congreso Internacional de Entomología. Madrid, 6-12 septiembre de 1935, Madrid, Laboratorio de Entomología del Museo Nacional de Ciencias Naturales, vol. 2, 621-633.

Sala, José (1982), “Cambio de paradigma y polémica científica entre los biólogos españoles (1860-1922)", Asclepio, 34, 239-263.

Salavert, Vicent (2006), "Ciència per correu. La comunicació científica: de la transmissió oral a la revista", Afers, 21 (53/54), pp. 11-35.

Sanz, Concepción (1992), "Naturalismo español y biogeografía". En: Gómez Mendoza, Josefina; Ortega, Nicolás (dir.), Naturalismo y geografía en España (desde mediados del siglo XIX hasta la Guerra Civil), Madrid, Fundación Banco Exterior, pp. 135-197.

Schmiedeknecht, Otto (1882-1886), Apidae Europaeae (Die Bienen Europa's) per Genera, Species et Varietates Dispositae atque Descriptae a Dr. [...], Gumperda/Berlín, Friedländer.

Schwartz, Joel S. (1995), “George John Romanes's Defense of Darwinism: The Correspondence of Charles Darwin and His Chief Disciple", Journal of the History of Biology, 28, pp. 281-316.

Schwartz, Joel S. (2010), Darwin's Disciple: George John Romanes, A Life in Letters, Philadelphia, American Philosophical Society.

Steiner, George (2004), Lecciones de los maestros. Trad. María Condor, Madrid, Siruela.

Vidal, Josep Manel (2006), "La vida quotidiana dels cientifics a través de les seues cartes. La correspondència entre Trèmols i Rodríguez Femenias", Afers, 21 (53/54), pp. 109-134.

Weidner, Herbert (1967), "Geschichte der Entomologie in Hamburg", Abhandlungen und Verhandlungen des Naturwissenschaftlichen Vereins in Hamburg, 9, supplement, 387 pp.

White, Paul (2009), "Introduction [The Emotional Economy of Science]", Isis, 100, pp. 792-797. 